\title{
Evaluation of generating mechanism of residential building patterns in contemporary cities. Case study on Xi'an and Nanjing
}

\author{
Ruoyao Li, Lian Tang, Wowo Ding* \\ School of Architecture and Urban Planning, Nanjing University, Nanjing, China \\ *(corresponding author) \\ E-mail: lilyhehua@163.com, tanglian@nju.edu.cn,dww@nju.edu.cn
}

\begin{abstract}
Residential area occupies a large portion of urban land, so it is very important to understand the characteristics of the residential building patterns and how such patterns, normally parallel multi-story and highrise slab apartments in various cities of China, are formed. The residential building patterns vary according to the living behavior, climate consideration, environmental requirement and market demands. Our previous studies have shown that sunshine regulation is by far the most important factor in the generation of the residential building pattern since 1980. This paper attempts to make a comprehensive evaluation to see the generating mechanism of the residential morphological patterns. Ten residential plots from two cities, Xi'an and Nanjing, located in different climate zones are evaluated. Five factors, namely, the type of the apartment, plot FAR, land coverage, sunshine regulations and spatial characteristics of plot pattern, will be used as comprehensive evaluation indicators in the comparison. The study reveals how these factors interplay in the generation of the observed plot patterns and which factor is the most important in this process. If the sunshine regulations were the key factor, how different the plot patterns in different climate zones and latitudes would have varied. Through evaluating generating mechanism we could find out the key generating factors, which is useful as the references for design.
\end{abstract}

Keywords: Residential building pattern, generating mechanism, living behavior, floor area ratio, sunshine regulations

\section{Introduction}

In the study of urban morphology, M.R.G Conzen holds that fundamental elements of physical built form are streets, plots and buildings. This has formed a morphological system of a complete body to a complete set though still with some ambiguities. The clarification of those relationships opens the way for potential advances (Kropf,2013). Plot is not the only generating factors of human settlements (Kropf,1997). Therefore, it is important to identify what the other generating factors of urban residential fabric are. This paper aims to study the generation mechanism of residential building patterns in context and in association with other aspects of urban form to supplement the classical theory.

With the development of China's urbanization in the past 30 years, the urban forms of the cities in China have undergone tremendous changes. The rapid growth of population in China has led to the increasing demand for residential buildings since the reform and opening up in 1978. At the same time, China has introduced and modified the housing standards. The residential fabric, which occupies the largest proportion of China's urban land, has gradually exhibited regular morphology characteristics, most of which consists of multi-story and high-rise buildings whose patterns are usually parallel- 


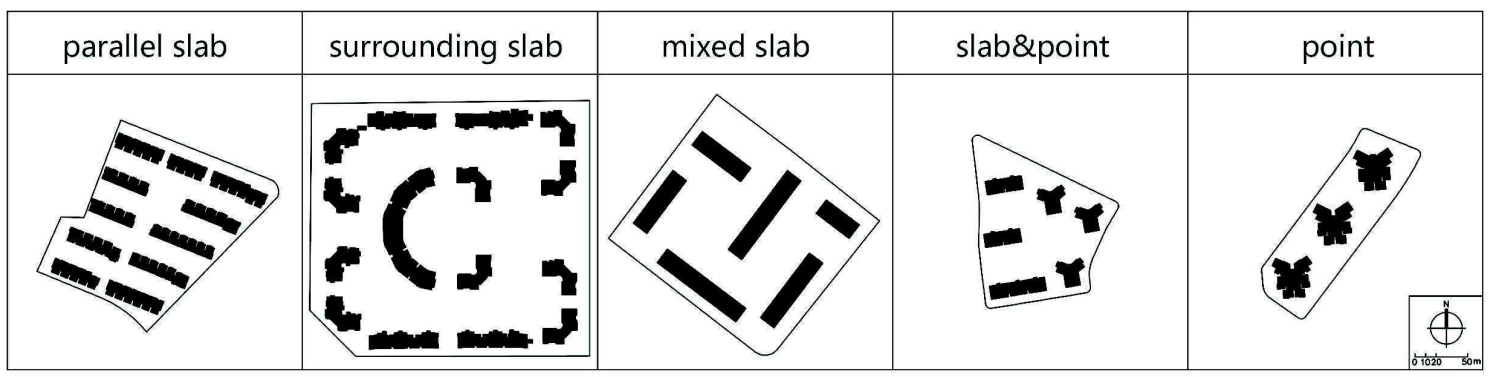

Figure 1-a 5 Residential Patterns in China
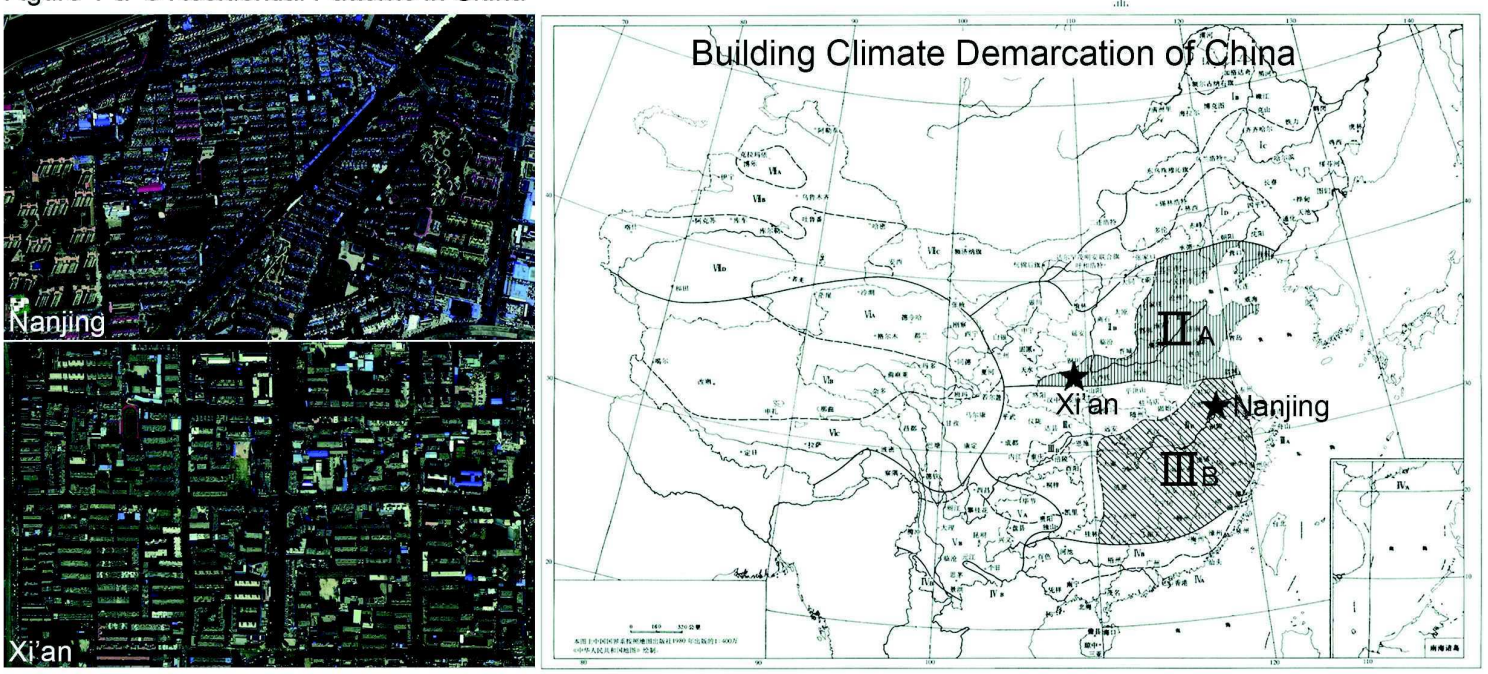

Figure 1-b Residential Fabric in Two Cities Figure 1-c Locations of Nanjing and Xi'an on Climate Demarcation Map

Figure 1.

a. 5 Residential Patterns in China

b. Residential Fabric in Two Cities

c. Locations of Nanjing and Xi'an on Climate Demarcation Map

slab or scattered-point in various cities of China. Therefore, it is essential to understand the characteristics of the residential building patterns and how such patterns are formed with regard to the study of contemporary urban morphology of China.

Related studies on the various generating factors of residential patterns fall into three groups. First, marketing demands which was indicated as the floor area ratio of plot are directly related to the height of residential buildings (Zhang, and Ding, 2012). Second, it has been proven clearly traditional living habit is an essential generating factor in the construction of traditional housing while living behavior in contemporary China mainly influence the shape of residential buildings (Liu, 2012). Third, climate environments, good sunshine and natural cross ventilation, are considered when arranging the residential buildings. Strict sunshine regulations which contribute to better living conditions greatly influenced the patterns since 1980s in China. These factors are interacted each other and emphasized differently. However, it is not clear how to quantify all these different factors. A large number of studies in China show that the sunshine is an important factor affecting the distribution of the pattern. However, it is not clear whether the sunshine is the most important factor or not and how it works in the generating mechanism. This paper attempts to find some relations between these factors and building patterns. It will not only contribute to the accurate study of urban morphology, but also provide a reference for more precise fabric formation of the residential plot.

The mentioned three factors, marketing demands, living habits and climate environment, may affect the housing patterns, which therefore need to be examined. With regard to the marketing demands, the amount of residential construction, which can be quantified by the floor area ratio (FAR) on the same area plot, 
is increasing with the development. However, residential buildings tend to get the maximum profit on the basis of meeting the requirements of the relevant laws and regulations even in different regions. In this case, the key factor in the process of generating residential patterns is then examined. Living habit and climate environment (sunshine and natural ventilation) can represent region characteristics of one city. To compare the different habits and climate environment, two major cities, Xi'an and Nanjing, which are located at completely different part of China, are selected. This paper attempts to explore the generation mechanism of Chinese contemporary settlements through the evaluation of these two cities.

\section{Study Material}

Residential building in China mainly consists of slab-type and point-type, and they are arranged as five basic patterns as shown in Figure 1-a: only parallel slab-type, surrounding slab-type, mixed slab-type, mixed slab and point-type and only point-type.

According to the statistics result of 2056 residential plots in Nanjing, the most residential plots are of parallel slab-type accounting for about 65\% (Zhao,2012). Meanwhile, at the beginning of the founding of PRC in the 1950s, the residential patterns in Xi'an, the northern part in China, highly influenced by the Soviet Union, were mainly the surrounding slabtype. With more and more emphasis on good sunshine and ventilation condition from the

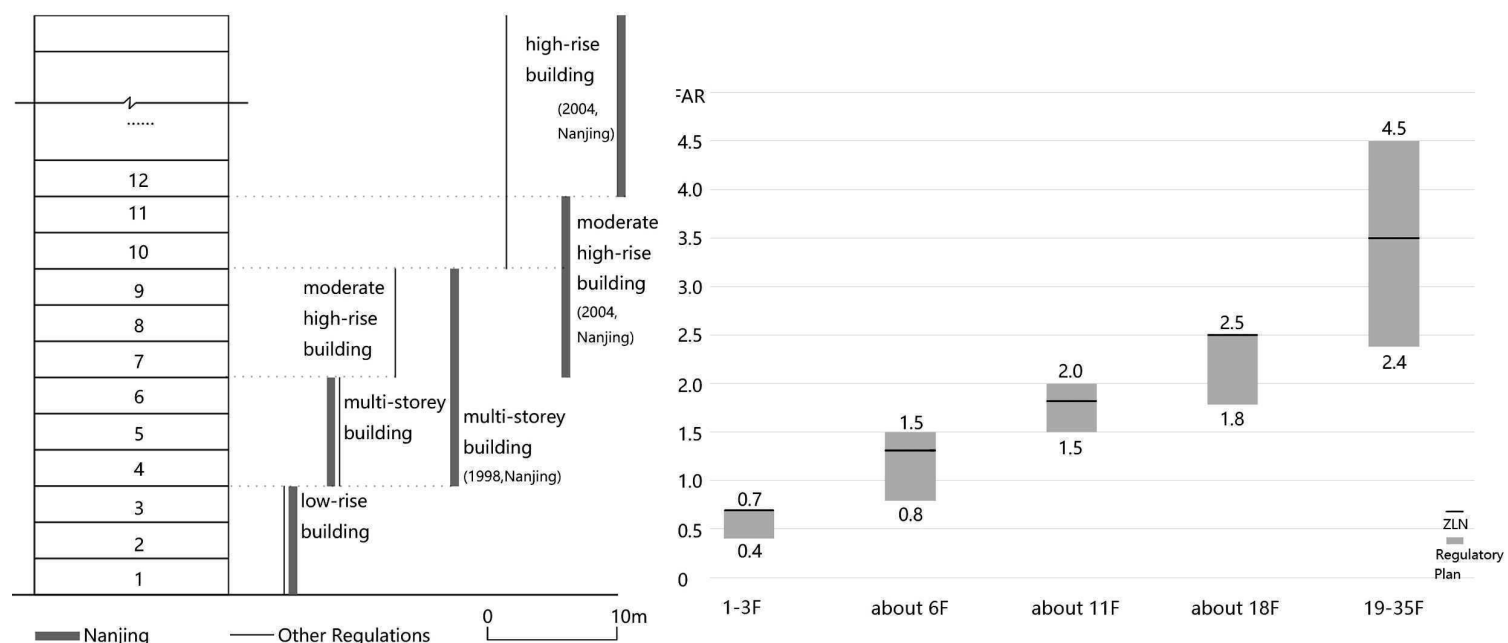

Figure 2-a Height type under the Laws
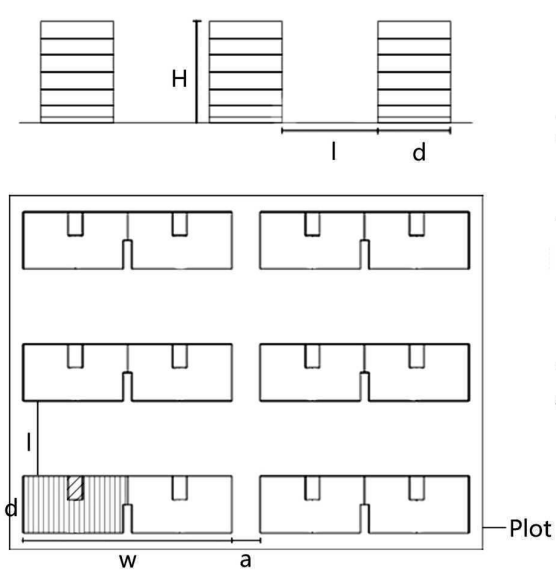

Figure 2-c Parallel Residential Building Pattern

Figure 2-b Relationship between Height Types and FARs

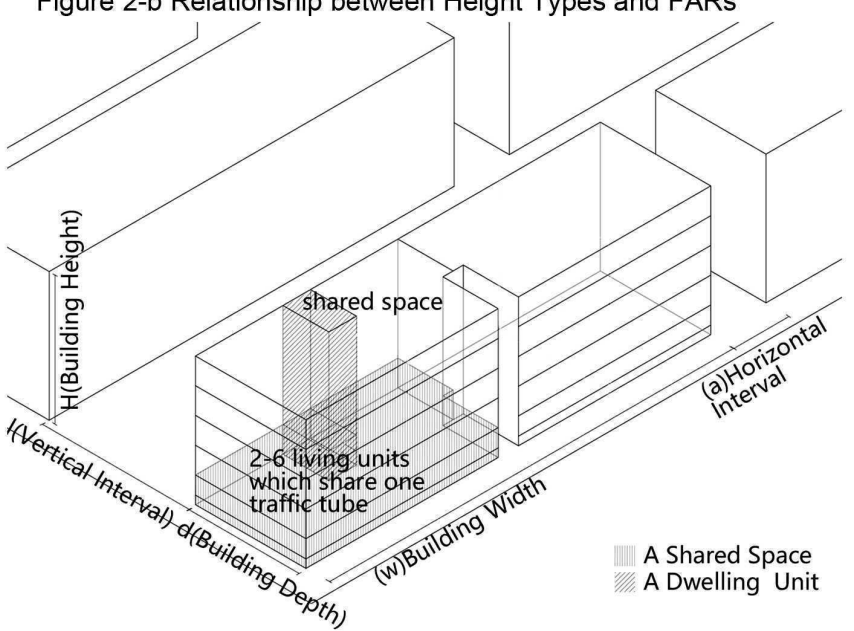

Figure 2.

a. Height Type under the Laws

b. Relationship between Height Types and FARs

c. Parallel Residential Building Pattern 
1980s, now the surrounding slab-type drops to less than $20 \%$, while the parallel slab-type accounts for more than $60 \%$ (Cui, 2013). It is interesting that the parallel slab-type has become the majority of settlement patterns in both Nanjing and Xi' an as shown in Figure 1-b.

Nanjing and Xi'an are located in different climate zones of China as shown in Figure 1-c, with completely different latitude and longitude. The latitude of Nanjing, located in southern China, is low, while it of Xi'an, located in northern China, is high. Nanjing has higher requirements for ventilation because of its humid climate. Xi' an is cold in winter, so it has a higher demand for warmth. Meanwhile the sunshine regulations and laws are different for both the solar elevation angle and sunshine duration since the different latitude and longitude of the two places.

\section{Market Demands}

Due to the restrictions on the fire safety laws when construction which stipulates what kind of staircase and elevator shafts are required for diverse floors of residential buildings and vertical traffic conditions, Code for Design of Civil Buildings divides the residential layer interval. 1-3 floor is low-rise residential building, 4-6 floor for the multi-story district, 7-9 floor for the moderate high-rise and more than 10 for the high-rise. Xi' an local norms is the same as the national laws. Nanjing local norms in 1998 stipulate 4-9 floor for multi-story while in 2004 4-6 floor is multi-story, 7-11 is moderate high-rise and more than 12 -floor or 35 meters is high-rise residential building (Figure 2-a). Parallel slab-type residential patterns in $\mathrm{Xi}$ 'an and Nanjing approach to the maximum layer under the fire safety law to get the most benefit, so about 6 - story account for the most of multi- story, about 11-story and 18-story for the high-rise. It shows a clear regularity which has a certain reference value on selecting the cases below.

The FAR of the plot as an index of the characteristics of the land, to a certain extent, can reflect the market demands. In the compiled various types of residential land in the detailed planning which is under the existing China's urban planning and regulatory system, the
FAR and the residential building height show a certain degree of correlation, a certain FAR has a corresponding height type, which was proved also on Zhang's paper on 2013 as shown in Figure 2-b.

So the relationship between market demands and residential patterns has been clarified, but the effect of living habits and climate environment on the parallel slabtype pattern is still worth discussing. Firstly, one floor of a slab residential building is constituted by 1-5 dwelling units, one of which are characterized by 2-6 living units and a shared space including stairs or elevators. A slab building was determined by the value of its height $(\mathrm{H})$, building width(w) and depth(d). When it combined in parallel together on a plot, the vertical interval(l) and the horizontal interval(a) are taken into account (Figure 2-c). Then, what values are affected by the living habits and climate environment, and when the plot area is certain, what the relationship between these values and the FAR of the plot.

\section{Living Habits}

In this study, we choose 12 parallel slab-type residential patterns which were constructed after the year of 1990 each in Nanjing and Xi'an. In all these cases, the plot contains only a single type of height type. No low-rise type was selected since few of them exists in reality. Each city has 6 multi-story type, which are around 6-floor, and 6 high-rise type broadly, which mostly consists of 11-floor and 18-floor residential buildings as shown in Figure 3-a.

Due to the impact of family planning policy, a typical Chinese family has about five persons with two or three generations living together, which requires 2-4 rooms. The case study of Nanjing has been proven that there are two types of the entry way to a living unit of a slab apartment, namely axis pattern and central pattern. Both entry ways require passing through a public apace in order to reach any private room. According to the similar way of entering home and the composition of function, the depth of a living unit varies between 11 and 20 meters (Liu, 2012). Living habit affect the depth of the housing building, then how the habits of different regions impact on the 
depth of a slab building. In order to clarify this question, the paper aims to do the comparison analysis of all the residential buildings in the cases.

First of all, find and count all 46 kinds of building depth which appear in 24 cases, compare Nanjing and Xi'an. Then, find out the various depth values in the 12 multi-story cases, compare Nanjing and Xi'an. Finally, compare the difference of monomer depth values between multi-story and high-rise cases. (Figure 4-a)

The following observations can be made from the statistical results:

a. Considering all types of building, the values of floor depth change in the range of 1018 meters. Nanjing's vary from 10 to 16 meters while Xi'an's vary from 12 to 18 meters. The majority of Nanjing's is in 12-13 meters while that of Xi'an is in 15-16 meters. Without considering the floor numbers, the average depth value of a building in $\mathrm{Xi}$ 'an is about 2-meter thicker than that in Nanjing.

b. Considering the multi- story type, the depth values approximately change in the range of 10-16 meters. Nanjing's vary from 10 to 14 meters while Xi'an's from 12 to 16 meters. The general trend is the same as considering all building types.

c. The multi-story's depth values range from 10 to 16 meters while the high-rise's data change from $10-18 \mathrm{~m}$. In general, the high-rise building is thicker than the multi-story building in both cities.

To summarize the above results, first of all, the depth value of Xian's building is bigger than Nanjing's on average. The variation is about 2 meters. To elucidate the reason behind this variation, a similar comparable living unit in Nanjing and Xian each is chosen for fully comparison. Both units have the same eastentry way and have of 3 bedrooms(B), 1 living room(L), 1 dining room(D), 2 washrooms(W), 1 kitchen $(\mathrm{K})$ and 1 or 2 balconies as shown in Figure 4-b. Each unit is south oriented and obeys the rule that every space has its own window. However, the size of rooms in Xi' an is bigger than that of in Nanjing. The living habits in Nanjing and Xi' an are similar, so the room function is similar. But the room size of Nanjing is slightly smaller than the room in Xi'an. This could be due to Nanjing's wet

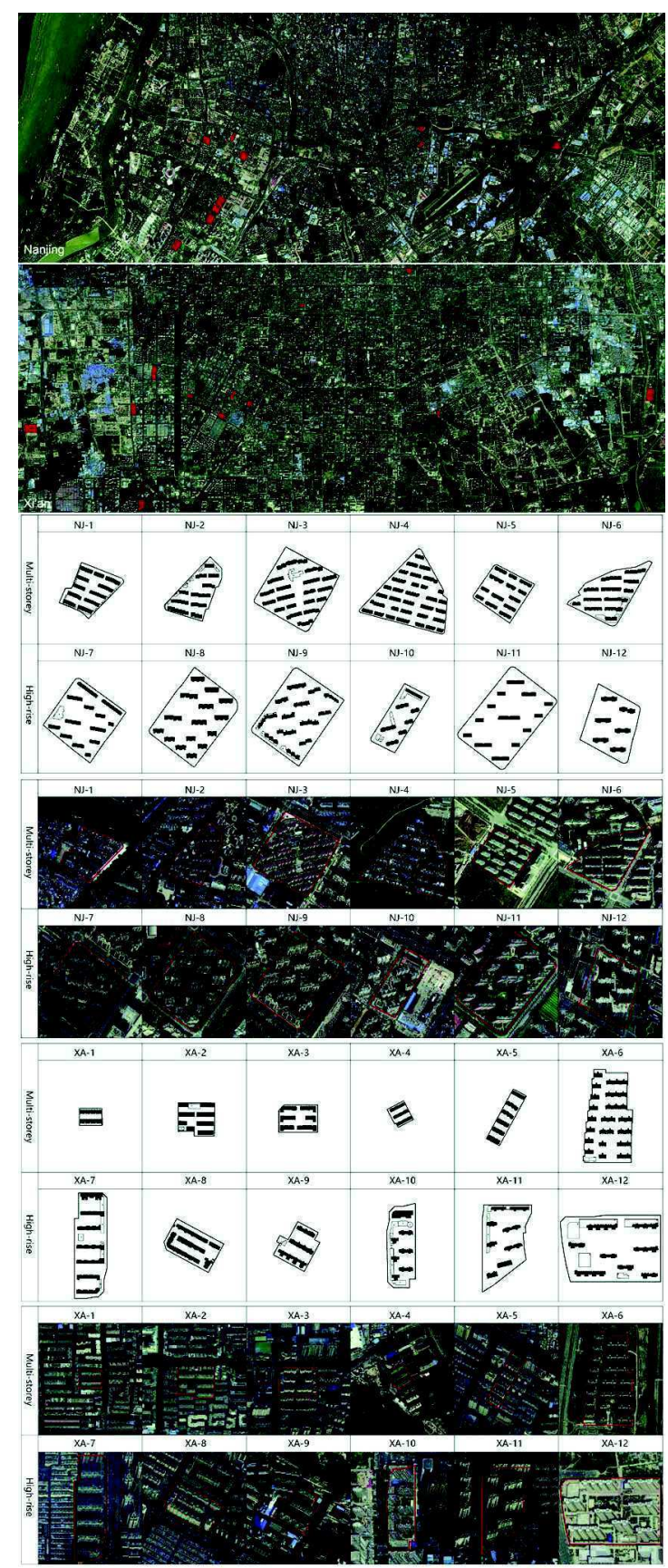

Figure 3.

All the study cases in Nanjing and Xi'an

and rainy weather. The thinner the building is, the more ventilation it can get. Xi'an is colder in Winter so the building generally is thicker to keep warm. Therefore, the difference in weather makes the depth of a single slab residential building in $\mathrm{Xi}^{\prime}$ 'an, on average, is thicker than that in Nanjing.

Secondly, high-rise building is usually thicker than multi-story building. This difference is usually the result of fire safety 


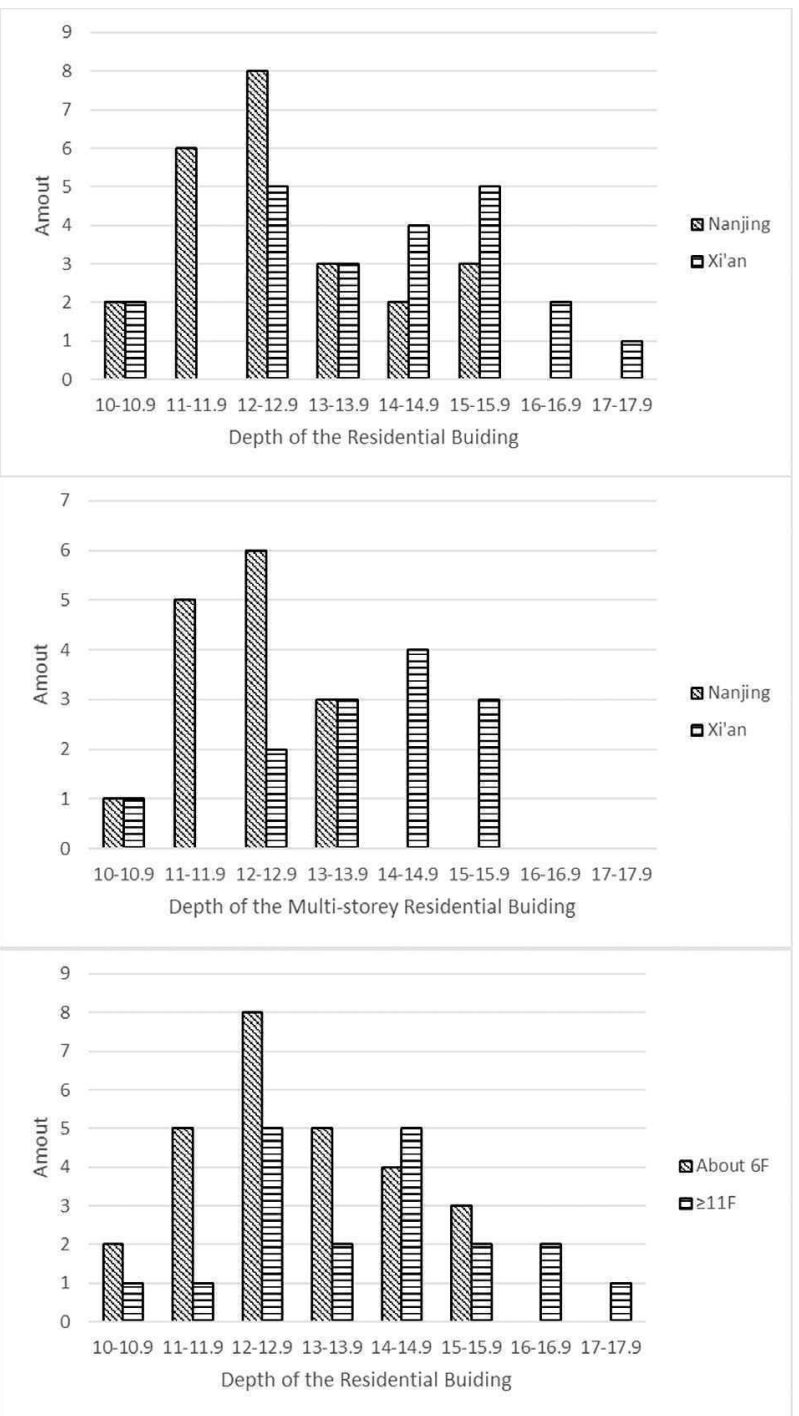

Figure 4-a Statistics of Slab Building Depths

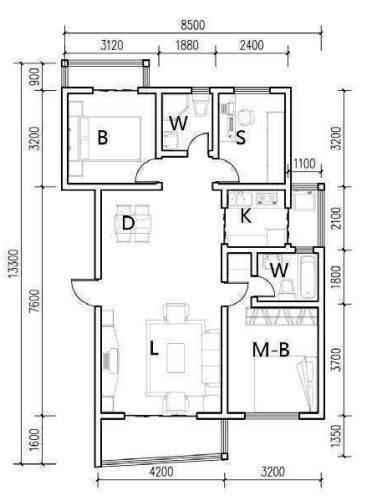

Nanjing Living Unit

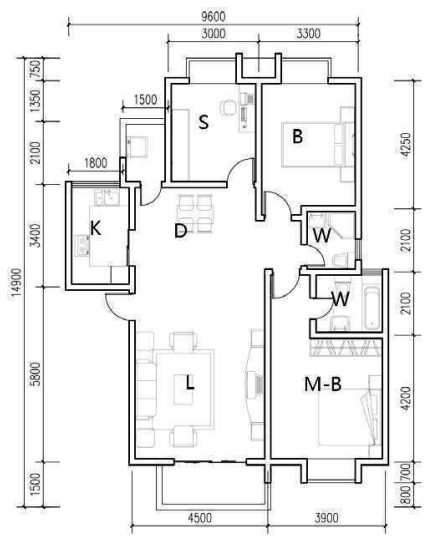

$\mathrm{Xi}^{\prime}$ an Living Unit

Figure 4-b Contrast of Living Units in Nanjing and $\mathrm{Xi}^{{ }^{\prime}}$ an

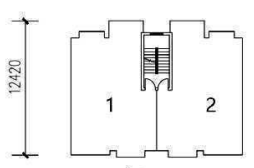

Multi-storey
Dwelling Unit

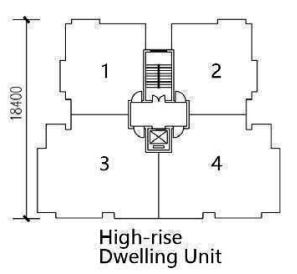

Figure 4-c Dwelling Units of Different Height Type

Figure 4.

a. Statistics of Slab Building Depths

b. Contrast of Living Units in Nanjing and Xi'an

c. Dwelling Units of Different Height Type 
and vertical traffic regulations. A high-rise dwelling unit can hold 4 or more apartments along with a shared space while a multi-story dwelling unit usually holds only 2 apartments along a staircase as shown in Figure 4-c.

Thus, the depth of a slab-type building changes according to the height type and the living habit. When the height type changes, the depth change is usually due to the number of living units and the different fire safety regulations or laws. When the living habit changes, the depth value of a slab building varies to accommodate the habit such as the weather consideration.

\section{Climate Environment (Sunshine)}

It is well known that living habits determine the depth value of a single slab residential building, however, it is not clear what role the climate environment plays in the generation mechanism. Quota targets of urban planning or the first time stipulated clear regulations on the vertical interval between two parallel slab buildings with south-north facing. After that, the current norms have strict rules for the vertical interval(1) between two slabs when they are south oriented. Although building's ventilation is closely related to the vertical interval as well, there is no clear standard for the relationship between them.

In the detailed local urban planning codes, the local governments consider many factors including regional solar elevation angle, effective sunshine duration, local economic level and the development of people living conditions. In order to simplify the calculation of the vertical interval in the residential pattern, an index called the coefficient of the buildings insolation interval (i) is usually used. Insolation internal is defined so that the shadow of one building at noon does not block the window of the other parallel slab building. The sun is always on the south side of the building in China as shown in Insolation interval (1) can be calculated as $\mathrm{h} / \tan \alpha$ as shown in Figure $5-\mathrm{a}$, where $\alpha$ is the solar elevation angle, and $\mathrm{h}$, is the height of the first build to the bottom windowsill of the blocked. In practice, the coefficient of the buildings insolation interval $(\mathrm{i}=1 / \mathrm{h})$ is used to calculate the insolation interval under the same situation. If the "i" value is bigger, the insolation interval decided by the sunshine condition will be bigger. Given a fixed plot area, the less number of buildings can be arranged.

This paper tries to evaluation the sunshine conditions in reality for the 24 residential patterns we have selected earlier in Nanjing and in Xi'an. All these patterns were built in the years from 1991 to 2014. If most of the real data from those building is in compliance with local regulations, we could say that sunshine determines the vertical interval in the residential building patterns.

First of all, the detailed regulations on sunshine of two different cities need to be sorted out clearly. Nanjing in year of 1987, 1995, 1998, 2004, 2007, 2011 formulated and modified sunshine regulations. At the same time, Xi'an introduced its own sunshine regulations in year of 1987, 1993, 2005, 2006, 2012. All the medium index for each regulation change and for both cities are listed in Table-1. In 2012's Xi regulation, "i" value as a function of sunshine angle is listed as in Table 1-b.

It can be seen from the table that the change of "i" value, i.e., $\mathrm{i}=\mathrm{h} / \mathrm{l}$, in 1987 and 1995 in Nanjing is reflected in the effective height of the building, and the similar trend can be found in 2005 and 2006 in Xi' an as well. To compare the reality with the regulations, it is essential to distinguish the difference of real building height $(\mathrm{H})$ and the sunshine calculation height (h). From the regulation in Table 1-a, it can be seen that the sunshine regulations were getting stricter as the land value kept increasing during these years. As the orientation of a slab building deviates from south to east or west, the "i" value also produces a reduction as shown in Table 1-b.

Secondly, we need to count and analyse the vertical intervals and " $i$ " values in the real cases. To do that, first we select the most unfavorable insolation interval position in each case and find out the construction year. Then, investigate whether $\mathrm{H}$ or $\mathrm{h}$ is used and calculate "i" value by the equation $\mathrm{i}=1 / \mathrm{h}($ or $\mathrm{H})$ in reality according to the detailed rules on sunshine regulations. After that, do the statistics of actual "i" value and make a comparison with the theoretical "i" value to find out the percentage of cases which conform to the specifications in total. Finally, 

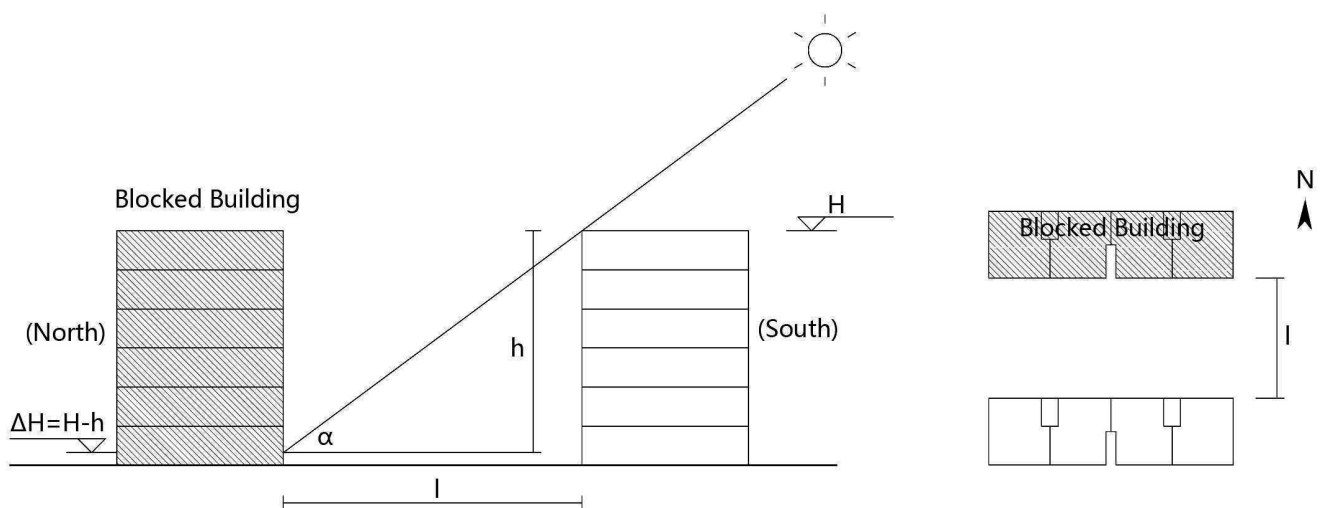

Figure 5-a The Situation of Insolation Interval and "i" Value Calculation

\begin{tabular}{|c|c|c|}
\hline Nation & $\begin{array}{l}1987 \\
1 \text { h sunshine duration } \\
\text { on Winter Solstice }\end{array}$ & \begin{tabular}{|l|}
1994 \\
$1 \mathrm{~h} / 2 \mathrm{~h}$ sunshine duration \\
on Major Cold
\end{tabular} \\
\hline \multirow[t]{2}{*}{ Nanjing } & $i=1: 1.36$ & $i=1: 1 \cdot 3-1: 1.33$ \\
\hline & $\begin{array}{l}1987 \\
i=1: 1-1: 1.2 \\
(<1 \text { on } W S)\end{array}$ & $\begin{array}{l}1995 \\
i=1: 1-1: 1.2 \\
(<1 \mathrm{~h} / 2 \mathrm{~h} \text { on } \mathrm{MC}) \\
2004 \\
\mathrm{i}=1: 25-1: 1.3 \\
(<1 \mathrm{~h} / 2 \mathrm{~h} \text { on } \mathrm{MC} \\
\text { better than } 1995)\end{array}$ \\
\hline \multirow[t]{2}{*}{$\mathrm{Xi}^{\prime}$ an } & $i=1: 1.48$ & $i=1: 1.31-1: 1.35$ \\
\hline & $\begin{array}{l}1987 \\
i=1: 1-1: 1.5 \\
(\leq 1 \mathrm{~h} \text { on WS })\end{array}$ & $\begin{array}{l}2005 \\
i=1: 1.31-1: 1.35 \\
(=1 \mathrm{~h} / 2 \mathrm{~h} \text { on } \mathrm{MC})\end{array}$ \\
\hline
\end{tabular}

\begin{tabular}{|c|c|c|c|}
\hline Pattern & & \\
& & & \\
\hline Location & $\mathrm{Xi}^{\prime}$ an & Nanjing & Nanjing \\
\hline $\mathrm{i}$ & $1: 1.0$ & $1: 1.0$ & $1: 1.3$ \\
\hline $\mathrm{d}$ & $14 \mathrm{~m}$ & $12 \mathrm{~m}$ & $12 \mathrm{~m}$ \\
\hline $\mathrm{h}$ & $15.9 \mathrm{~m}$ & $15.9 \mathrm{~m}$ & $15.9 \mathrm{~m}$ \\
\hline $\mathrm{I}$ & $15.9 \mathrm{~m}$ & $15.9 \mathrm{~m}$ & $20.7 \mathrm{~m}$ \\
\hline $\begin{array}{c}\text { Sunshine } \\
\text { Duration }\end{array}$ & $<2 \mathrm{~h}(\mathrm{~min})$ & $<2 \mathrm{~h}(\mathrm{mid})$ & $<2 \mathrm{~h}(\mathrm{max})$ \\
\hline FAR & $2.58(\mathrm{max})$ & $2.22(\mathrm{mid})$ & $1.9(\mathrm{~min})$ \\
\hline
\end{tabular}

Figure 5-b National and Regional Sunshine Regulations Figure 5-c Hypothetical Pattern according to the Laws

\begin{tabular}{|l|l|l|l|l|l|l|l|l|}
\hline \multicolumn{1}{|c|}{ Pattern } & Plot Area $\left(\mathrm{m}^{2}\right)$ & Actual "i" value & $\mathrm{d}(\mathrm{m})$ & $\mathrm{h}(\mathrm{m})$ & $\mathrm{Imin}(\mathrm{m})$ & Sunshine Duration & FAR \\
\hline NJ-3 & 48313.4 & 1.36 & 12.7 & 15.9 & 21.7 & $>2 \mathrm{~h}(\mathrm{mid})$ & $1.34(\mathrm{mid})$ \\
\hline & & & & & & & & \\
\hline
\end{tabular}

Figure 5-d Three chosen cases to Verify the Hypothesis

Figure 5.

a. The Situation of Insolation Interval and "i" Value Calculation

b. National and Regional Sunshine Regulations

c. Hypothetical Pattern according to the Laws

d. Three chosen cases to Verify the Hypothesis

find out the percentage of it in multi-story and high-rise groups.

Of all the building types, $71 \%$ of them meet the sunshine regulations. For the multi-story type, $83 \%$ meet the regulations while, for high-rise one, only $58 \%$ meets the sunshine regulations.

The sunshine codes published by Nanjing in 2004 pointed out that moderate high-rise slab buildings can also use the "i" value as a measurement. So this paper compares the high-rise buildings also. However, in all cases, there are not only moderate high-rise buildings but also more than 18 -floor high-rise buildings. With the floors increase, the type of residential building monomer has changed. The impact of sunshine on housing has become more complex, so, the coefficient "i" value is 
no longer the only index that influences the intervals. Therefore, it can be concluded that sunshine is the key factor to determine the vertical interval between slab buildings in the parallel multi-story residential patterns.

Then, how does sunshine affect the slab multistory housing patterns? The national sunshine codes prescribe the rules by specifying the minimum sunshine duration hours at the most unfavorable position of a building on Winter Solstice (December 22nd) or Major Cold (January 20th). In the national code, although Nanjing and Xi'an belong to different climate demarcation (according to Building Climate Demarcation Map of China, 1993, Figure 2), both cities are required to meet sunshine regulations. In 1980, national code put forward laws on the insolation interval for the first time. The law requires at least 1-hour sunshine inside a bottom living unit of a building on Winter Solstice locally. In 1987, more details regulations were added to the law, saying that at least 1 room in a living unit should have 1-hour sunshine duration on Winter Solstice. In 1994, the sunshine specification stipulates at least 2-hour sunshine duration in a room of a living unit on Major Cold. Because the solar elevation angle is bigger than that on Winter Solstice, it was adjusted to reduce the standard though the duration seems to be longer. Although the requirements in specification are the same, Nanjing and Xi'an differ in local effective sunshine duration, solar elevation angle. Local planning bureaus in accordance with national norms develop local implementation details or technical rules. In theory, local bureaus try to calculate the " $\mathrm{i}$ " value to meet the sunshine duration regulations through the established standard models according to its local geographic location.

To meet the 1-hour sunshine duration on Winter Solstice in 1987 national code, the theoretical " $i$ " value is 1.36 in Nanjing, but the details in local code set "i" equal minimum 1 and maximum 1.2 while in Xi' an the theoretical one is 1.48 , the local " $i$ " from 1 to 1.5 . In this case, planning a new residential pattern only met the minimum "i" to get more profit. At that time, there was almost no urban residential area to meet the requirements, it is clear that the standard of 1 -hour sunshine duration on Winter Solstice is too strict. In
1994, nation code set that at least 2-hour sunshine duration in a room of a living unit on Major Cold. The Nanjing "i" should be 1.33 while in 1995 " $\mathrm{i}$ " is 1.2 and in 2004 " $\mathrm{i}$ " is 1.3 in new district to approach the national code. Meanwhile, Xi'an's should be 1.35 and its details regulations in 2005 meet the standard. (Figure 5-b) In order to reduce the coefficient of the insolation interval, local codes tend to reduce the sunshine duration inside the living units as possible. Sunshine regulations and laws are affected by changing the number of sunshine hours to control the vertical intervals in the slab multi-story residential patterns.

So, it can be assumed that if arrange the same height slab residential patterns on 2 same area plots in a place which has a certain living habit, if the buildings have less sunshine duration, in theory, the vertical interval between buildings is smaller, the FAR will be bigger. It should be considered that the depth of a monomer in Xi'an has been proved thicker than that in Nanjing when comparing them. According to the code, establish three residential patterns of 6-story with same area plot in Xi'an and Nanjing. One pattern of $\mathrm{i}=1$ in $\mathrm{Xi}$ 'an and Nanjing accounts for two of $i=1$ and $i=1.3$. Set the most popular size $200 * 200$ meters of a plot, depth of 12 meters for Nanjing slab building while 14 for Xi' an as proved, 88-meter building length of 4 dwelling units for one dwelling unit is about $22 \mathrm{~m}$ (Zhang Lina,2012). (Figure 5 -c) It can be seen that when the plot area is the same, when sunshine duration in Xi'an is shorter than Nanjing for that they have a same " $i$ " value and Xi' an located in the higher latitude, the FAR of Xi' an is larger. And as the sunshine specification of Nanjing changes with the year, when the sunshine duration adds, the FAR will decline when the plot area is fixed. If the assumption is true, it can be proved that in actual, sunshine hours that a living unit can be shined will directly affect the FAR of parallel multi-storey residential patterns. Longer sunshine duration results in lower FAR.

Three patterns which are similar in plot area from the 24 cases to verify the assumption was chosen. One of the 3 cases is in Xi' an and other are in Nanjing. Court the d, h, " $i$ " values, sunshine durations and FARs of these cases and make a table. We can see that when the plot area is certain, sunshine duration and FAR are 
in inverse relationship just as the assumption. (Figure 5-d)

\section{Conclusion and Discussion}

As the rapid expansion of urburn redisential area, it is important to understand the generation mechansim of the residential patterns. This paper tries to find out the effect of market demands, living habits and climate environment on the generation mechanism of housing pattern. Based on the relevant regulations, this paper studies the slab settlements in Xi'an and Nanjing and compares them with indexes such as the depth of the living unit, the coefficient of the vertical interval between buildings, sunshine duration, FAR and so on. The conclusions are as follows:

-First, the FAR, which can reflect market demands, and the residential building height are directly correlated, i.e., a certain FAR has a corresponding height type.

-Second, the height type and the living habit influence the depth of a slab building in parallel residential patterns.

-Third, sunshine condition determines the vertical interval of buildings in multistory parallel settlements even in different regionswhich has different sunshine duration.

The results can be used as reference in for the future study of urban morphology and exploration of its generation. While, sunshine and natural ventilation become increasingly important in climate and environment. And many people are studying the indexes of them and their correlation with patterns. In this paper, we have come to the conclusion that the sunshine has affected housing through the sunshine index. However, the impact of wind environment on settlements is rarely mentioned in regulations, and there are no good measures and policies related to ventilation. The residential patterns may change once ventilation indexes are defined by laws in the future.

Back to Kropf's theory on ambiguity of plot and building, it can be seen that once the given region has fixed living habits and clear environmental indicators in laws, the regular residential building pattern is traceable. This paper not only contributes to the study of the generation mechanism of residential patterns, but also to some extent responds to some theoretical studies.

Back to Kropf's theory on ambiguity of plot and building, it can be seen that once the given region has fixed living habits and clear environmental indicators in laws, the regular residential building pattern is traceable. This paper not only contributes to the study of the generation mechanism of residential patterns, but also to some extent responds to some theoretical studies.

\section{Acknowledgements}

This study was financially supported by National Natural Science Foundation of China (No.51538005).

\section{References}

Conzen, M. R. G. (1960) 'Alnwick, Northumberland: A study in town-plan analysis', in Institute of British Geographers Publication 27 (George Philip, London).

Cui G. (2013) 'Research of the Relationship between Changes of Sunlight Regulations and Residential Area Form: A Case Study of China, Japan and Korea', New Architecture 2013(2),108-111.

Kropf, K. S. (1997) 'When is a plot not a plot: problems in representation and interpretation', unpublished paper presented to the 4th ISUF, Birmingham, England.

Kropf, K. S. (2014) 'Ambiguity in the definition of built form', Urban Morphology 18(1),4157.

Liu, Q. (2012) 'Morphological Study on Units of Urban Fabric that Constitute Contemporary Residential Plots in the Yangtze River Delta, China', ISUF 19th Conference, Delft.

Zhang, L. and Ding, W. (2012) 'Density, height limitation, and plot pattern: quantitative description of the residential plot in Nanjing China', ISUF 19th Conference, Delft.

Zhao Q. (2012) 'Study and Description of Morphological Characteristics of Residential Plots: Based on a General Survey in Nanjing', unpublished Master thesis, Nanjing University, China. 
Quota Targets of Urban Planning (1980)

Code for Design of Civil Buildings (JGJ37-87)

Code for Design of Civil Buildings (GB 503522005)

Code for Planning and Design of Residential Area (GB50180-93)

Code for Design of Residential Buildings (GB50096-2011)

Code of Design on Building Fire Protection and Prevention (GB50016-2006)

Interim Provisions on the Management of Urban Construction in Nanjing (1987)
Details of Nanjing Urban Planning Regulations $(1995,1998,2004,2007)$

Technical Regulations for Urban Planning Management in Jiangsu Province (2011)

Xi'an Urban Construction Planning and Management Regulations (1987)

Xi'an Urban Planning and Management Regulations (1987)

Details of Xi'an Urban Planning Regulations (2005)

Technical Regulations for Urban Planning Management in Shaanxi Province (2006)

\section{Appendix}

Table 1-a “i” values in the Sunshine Regulations of Nanjing and Xi'an

\begin{tabular}{|l|l|l|l|l|l|}
\hline \multicolumn{2}{|l|}{ Nanjing } & Xi'an \\
\hline Year & $\begin{array}{l}\text { New City } \\
\text { District }\end{array}$ & $\begin{array}{l}\text { Old City } \\
\text { District }\end{array}$ & Year & $\begin{array}{l}\text { New City } \\
\text { District }\end{array}$ & $\begin{array}{l}\text { Old City } \\
\text { District }\end{array}$ \\
\hline 1987 & $\mathrm{H}: 1=1: 1.2$ & $\mathrm{H}: 1=1: 1$ & $1987(1993)$ & \multicolumn{2}{|c|}{$\mathrm{H}: 1=1: 1.1-1: 1.5$} \\
\hline $1995(1998)$ & $\mathrm{h}: 1=1: 1.2$ & $\mathrm{~h}: 1=1: 1$ & 2005 & \multicolumn{2}{|c|}{$\mathrm{H}: 1=1: 1.35$} \\
\hline $2004(2007)$ & $\mathrm{h}: 1=1: 1.30$ & $\mathrm{~h}: 1=1: 1.25$ & 2006 & h:l=1:1.35 & h:l=1:1.31 \\
\hline
\end{tabular}

Table 1-b The Reduction of Insolation Intervals of Various Directions

\begin{tabular}{|l|l|l|l|l|l|}
\hline Angel(deviates from south) & $0-15^{\circ}$ & $14-30^{\circ}$ & $30-45^{\circ}$ & $45-60^{\circ}$ & $\geq 60^{\circ}$ \\
\hline Vertical Interval & 1 & 0.91 & 0.81 & 0.91 & 0.951 \\
\hline
\end{tabular}

